\title{
AVALIAÇÃO E DIAGNÓSTICO DAS CONDIÇÕES DE COMERCIALIZAÇÃO DE ALIMENTOS NAS FEIRAS LIVRES NO ESTADO DA PARAÍBA
}

\author{
Cácio Ribeiro Cavalcanti \\ Flávia de Oliveira Paulino ${ }^{2}$ \\ Kalinne Duarte Gonçalves Mayer ${ }^{3}$ \\ Francisca Flávia da Silva ${ }^{3}$ \\ Veruska Dilyanne Silva Gomes ${ }^{4}$ \\ Francisco Glauco de Araújo Santos ${ }^{5}$
}

CAVAlCANTI, C. R.; PAUlinO, F. de O.; MAYER, K. D. G.; SILVA, F. F. da; GOMES, V. D. S.; SANTOS, F. G. de A. Avaliação e diagnóstico das condições de comercialização de alimentos nas feiras livres no estado da Paraíba. Arq. Ciênc. Vet. Zool. UNIPAR, Umuarama, v. 17, n. 3, p. 167-172, jul./set. 2014.

RESUMO: A comercialização de alimentos em feiras livres, expostos em barracas sem refrigeração e sem proteção pode alterar a qualidade dos alimentos. Alimentos crus e mal conservados podem ser veículos de contaminação por microrganismos causadores de toxinfecção e, dessa forma, colocar em risco a saúde do consumidor. Objetivou-se neste trabalho avaliar e definir um diagnóstico de feiras livres realizadas em quatros municípios paraibanos, localizados na mesorregião do Agreste: Campina Grande, Esperança, Areia e Bananeiras. Utilizou-se como metodologia o estudo analítico, por meio de um roteiro de observação pré-confeccionado, baseado nas recomendações da Agência Nacional de Vigilância Sanitária. O roteiro de observação do tipo checklist foi dividido em quatro seções: aspectos físicos, aspectos higiênicos, aspectos ambientais e aspectos organizacionais. Os resultados foram bastante insatisfatórios, tendo em vista que nos quatro aspectos de avaliação todos os municípios apresentaram pouquíssima conformidade. Do ponto de vista de saúde pública, as condições higiênicas de comercialização de alimentos mostraram-se precárias, principalmente, porque um grande número de pessoas fazem uso deste tipo de comércio para a aquisição de alimentos nas regiões estudadas. Foi permitido concluir que se faz necessário a implantação de políticas sociais e educacionais direcionadas para as feiras livres no estado da Paraíba.

PALAVRAS-CHAVE: Qualidade. Saúde Pública. Segurança Alimentar.

\section{EVALUATION AND DIAGNOSTIC OF FOOD SALE CONDITIONS IN STREET MARKETS IN THE STATE OF} PARAIBA, BRAZIL

\begin{abstract}
The trading of food in street markets exposed in tents without refrigeration or protection can change its quality. Raw and poorly preserved foods can become vehicles of contamination by microorganisms causing poisoning, and thus jeopardizing the health of the consumers. The objective of this study is to evaluate and define a diagnosis of street markets held in four cities in Paraiba, located in the middle region of the Wasteland: Campina Grande, Esperança, Areia and Bananeiras. The analytic study was used as methodology, by means of a previously made observation script, based on the recommendations from the National Health Surveillance Agency. The observation checklist script was divided into four sections: physical aspects, hygiene aspects, environmental aspects and organizational aspects. The results were quite unsatisfactory considering that in the four evaluation aspects, all municipalities showed very little conformity. From a public health point of view, the hygienic conditions of food trading proved to be precarious, mainly because a large number of people make use of this type of commerce for purchasing food in the regions studied. Therefore, it can be concluded that it is necessary to implement social and educational policies directed to street markets in the state of Paraiba.
\end{abstract}

KEYWORDS: Quality. Public health. Food security.

\section{EVALUACIÓN Y DIAGNÓSTICO DE LAS CONDICIONES DE COMERCIALIZACIÓN DE ALIMENTOS EN LAS FERIAS LIBRES EN EL ESTADO DE PARAÍBA, BRASIL}

RESUMEN: La comercialización de alimentos en ferias libres, expuestos en tenderetes de feria sin refrigeración y sin protección adecuada, puede cambiar la calidad de los mismos. Los alimentos crudos y pobremente mantenidos pueden ser vehículos de microorganismos que causan toxiinfección, poniendo por lo tanto en peligro la salud del consumidor. El objetivo de este estudio fue evaluar y definir un diagnóstico de las ferias libres realizadas en cuatro ciudades de Paraíba, localizadas en la región media del Agreste: Campina Grande, Esperança, Areia y Bananeiras. Se ha utilizado como metodología el estudio analítico, por medio de una guía de observación previamente realizada, basada en las recomendaciones de la Agencia Nacional de Vigilancia Sanitaria. La investigación fue realizada a partir de la observación del tipo checklist en cuatro secciones:

DOI: https://doi.org/10.25110/arqvet.v17i3.2014.4939

${ }^{1}$ Zootecnista, Mestrando no programa de pós graduação em Tecnologia Agroalimentar - Universidade Federal da Paraíba.

${ }^{2}$ Professora Dra. Da Universidade Federal da Paraíba.

${ }^{3}$ Graduanda em Medicina Veterinária pela Universidade Federal da Paraíba.

${ }^{4}$ Zootecnista. Doutoranda no Programa de Doutorado Integrado em Zootecnia - UFPB. veruska_sgomes@yahoo.com.br

${ }^{5}$ Professor Doutor da Universidade Federal do Acre.

Endereço para correpondência: Rua Horácio Trajano de Oliveira, nº 1914, Cristo Redentor - João Pessoa - PB. Cep: $58071-160$ 
aspectos físicos, higiénicos, ambientales y organizacionales. Los resultados fueron poco satisfactorios, considerando que en los cuatro aspectos evaluados todas las municipalidades mostraron inconformidad. Desde el punto de vista de la salud pública, las condiciones higiénicas de comercialización de alimentos demostraron ser precarias, aunque un gran número de personas hacen uso de este tipo de comercio para la adquisición de alimentos en las regiones estudiadas. Concluimos que se hace necesaria la implantación de políticas sociales y educativas dirigidas a las ferias libres en el estado de Paraíba.

PALABRAS CLAVE: Cualidad. Salud pública. Seguridad alimentar.

\section{Introdução}

A feira livre é um dos métodos de comércio mais antigos existentes no mundo. As feiras são fenômenos econômicos-sociais muito antigos e já eram conhecidas dos Gregos e Romanos. Para estes últimos, por causa das implicações de ordem pública que as feiras tinham, estabeleceu-se que as regras de sua criação e funcionamento dependiam da intervenção e garantia do estado. O papel das feiras tornou-se verdadeiramente importante a partir da chamada revolução comercial, ou seja, a partir do século XI. Daí em diante seu número foi sempre aumentando até o século XIII (ENCICLOPÉDIA LUSO-BRASILEIRA, 1995). A feira livre no Brasil constitui modalidade de mercado varejista ao ar livre, de periodicidade semanal, organizada como serviço de utilidade pública pela municipalidade e voltada para a distribuição local de gêneros alimentícios e produtos básicos. Desempenham papel relativamente importante no abastecimento urbano, apesar das políticas públicas adversas que tiveram de enfrentar nos últimos 30 anos (MASCARENHAS; DOLZANI, 2008).

Os mercados e feiras livres ocupam lugares de destaque no setor de alimentação. Nesses locais é comum que barracas convivam lado a lado, fazendo com que as condições higiênico-sanitárias inadequadas de uma tornem-se perigosas para as outras (CAPISTRANO et al., 2004). Geralmente, as áreas de venda localizadas em feiras livres apresentam infraestrutura inadequada, falta de acesso à água potável e às instalações sanitárias, o que faz aumentar os riscos de servirem como veículos de doenças. Os alimentos vendidos nas feiras populares em geral, são caracterizados pelo baixo preço, familiaridade, conveniência e fácil acesso (HANASHIRO et al., 2002).

Diversos trabalhos demonstram que a criação de espaços para a comercialização direta de alimentos por produtores, como as feiras livres, alcança resultados expressivos para compradores e vendedores. Para Ribeiro et al.(2005), quanto menor o município, maior costuma ser o impacto das feiras. De acordo com esses autores, os produtores ganham porque garantem a comercialização da produção, que de outra forma seria difícil nessas economias de pouca liquidez. Os consumidores ganham porque têm garantido um abastecimento regular, de qualidade e, principalmente, adaptado aos seus hábitos alimentares. E, por fim, ganham os comerciantes, uma vez que terminada a feira, os feirantes vão ao comércio e adquirem bens de consumo.

Presente em quase todas as cidades brasileiras, as feiras têm uma grande vinculação com a região Nordeste do Brasil, já que é a partir destas, que ocorre o abastecimento das mercadorias destinadas a atender às necessidades da população caracterizando a presença de um mercado periódico, típico de países subdesenvolvidos, que também atrai consumidores de cidades próximas, gerando fluxos de pessoas, capitais e mercadorias (SILVA et al., 2009).
De acordo com Correia e Roncada (1997), a comercialização de alimentos de origem animal em feiras livres, expostos em barracas sem refrigeração, sem proteção e na presença de poeira e insetos pode alterar a qualidade dos alimentos. Alimentos crus, comercializados em feiras livres e mercados públicos podem ser veículos de contaminação de microrganismos causadores de toxinfecção e desta forma, colocar em risco a saúde do consumidor.

Deve-se considerar ainda que nas feiras livres os alimentos de origem animal e seus produtos derivados ficam expostos sob condições insalubres, sujeitos às ações diretas dos microrganismos, sejam eles patogênicos ou apenas deteriorantes. Esses microrganismos são provenientes da contaminação do ambiente, da poluição ambiental, de insetos e da própria embalagem, quando não estão devidamente acondicionados ou embalados (GERMANO; GERMANO, 2000).

Como principais fatores relacionados à ocorrência de doenças de origem alimentar existem a má condição de higiene na manipulação dos alimentos, o uso incorreto do binômio tempo-temperatura, más condições de armazenamento e conservação dos alimentos e falta de adequação e conservação da estrutura física dos estabelecimentos. É importante ressaltar que a responsabilidade de oferecer alimentos seguros compete a todos envolvidos na cadeia produtiva. Esta cadeia é bastante complexa, envolvendo setores como: a produção de alimentos no campo, o processamento, o transporte, a conservação e a comercialização. Todos esses setores podem influenciar direta ou indiretamente a qualidade dos alimentos oferecidos (SILVA JÚNIOR, 2001). É importante ressaltar que atender as necessidades dos consumidores com maior eficiência é a base conceitual de toda estratégia. Entretanto, não se pode esquecer que a segurança sanitária dos produtos comercializados é inerente às necessidades do consumidor (DIB, 1997).

O objetivo deste estudo foi realizar um diagnóstico a partir dos aspectos físicos, higiênicos, ambientais e organizacionais em feiras livresde quatro municípiosdo Estado da Paraíba: Campina Grande, Esperança, Areia e Bananeiras.

\section{Material e Métodos}

Para este estudo foram escolhidas quatro municípios do estado da Paraíba: Campina Grande, Esperança, Areia e Bananeiras, todos localizados na mesorregião do Agreste Paraibano. Campina Grande e Esperança foram escolhidos devido à importância econômica para a região do Agreste. Os outros dois municípios, Areia e Bananeiras, concentram polos universitários importantes no estado da Paraíba.

Em função da ausência de legislação específica para feiras livres, optou-se pela realização do estudo analítico, utilizando como ferramenta de pesquisa um roteiro de observação pré-confeccionado, com base em recomendações da Agência Nacional de Vigilância Sanitária (BRASIL, 2004), previamente testado. O roteiro de observação do tipo 
checklist foi dividido em quatro seções: aspectos físicos, aspectos higiênicos, aspectos ambientais e aspectos organizacionais. Utilizou-se questionário fechado em todo roteiro, aplicado por pessoa previamente treinada, onde as respostas possíveis eram "sim" ou "não".

$\mathrm{Na}$ primeira seção, referente à estrutura física, os itens avaliados foram: impermeabilização de pisos e paredes, presença de sanitários, presença de água potável, ventilação e exaustão adequadas e disponibilidade de frio para armazenamento de alimentos perecíveis. Na segunda seção foram avaliadas as condições higiênico-sanitárias, tanto dos manipuladores de alimentos, como dos alimentos expostos à venda. Nesta seção foram avaliados os seguintes aspectos: adequação das condições higiênico-sanitárias para a comercialização de alimentos, responsabilidade pela higiene do local, higiene das bancadas e demais estruturas, treinamento em relação às boas práticas de manipulação de alimentos e uso de avental e touca pelo feirante.

A terceira seção do questionário foi utilizada para avaliar as questões ambientais. Foram observados a presença de pragas urbanas e animais errantes e a presença de dispensário para lixo para feirantes e consumidores. A última seção do questionário foi destinada à observação das características organizacionais das feiras livres. Nesta seção foram avaliados aspectos administrativos que permitem melhor organização deste tipo de comércio. Foram observados se havia separação de alimentos por categorias para venda, se os feirantes possuíam cadastro, se os boxes de comercialização eram devidamente identificados.

As respostas dos roteiros de observação foram transpostas para uma planilha no aplicativo Microsoft Office Excel ${ }^{\circledR}$, constituindo assim um banco de dados. Este passoupor uma codificação dos dados obtidos in locu e, posteriormente, foram compilados em tabelas de análise descritiva que mostravam as frequências de cada município avaliado.

\section{Resultados e Discussão}

Por meio do estudo e das observações nos quatro municípios alvo do estudo destacaram-se mais pontos negativos do que positivos. A avaliação dos aspectos físicos estão demonstrados na Figura 1. Em relação à impermeabilização, as cidades de Esperança e Bananeiras apresentaram 100\% das estruturas de piso e parede sem impermeabilização. Esses dados mostram uma certa preocupação, tendo em vista que a ausência de impermeabilização dificulta o processo de higienização. Em Campina Grande o nível de impermeabilização foi visto em $94,1 \%$ e em Areia foi de $88,6 \%$, o que foi bastante satisfatório. No item existência de pia com água correnteos resultados foram insatisfatórios. O município que apresentou maior nível de conformidade foi Campina Grande, com 12,3\%, seguido de Esperança (10,6\%), Areia $(7,6 \%)$ e Bananeiras (3,4\%). Esses resultados mostram preocupação, uma vez que os boxes de comercialização não dispõe de água para eventual limpeza e higienização dos manipuladores e das estruturas envolvidas. Na pesquisa de Mallon e Bortozolo (2004) apenas 13\% dos locais avaliados possuíam água, a qual era transportada em galões e proveniente da residência dos vendedores. Esses dados são semelhantes aos observados neste estudo e comprovam que a ausência de água limpa e corrente em feiras livres é uma constante em diferentes re- giões do Brasil.

No item presença de sanitários, observou-se precariedade deste tipo de estrutura nos quatros municípios. Esses dados são semelhantes aos encontrados por Silva, Matté e Matté (2008), uma vez que estes autores relataram que em feira livre de pescados em São Paulo não existem sanitários, água potável e energia elétrica disponível para os feirantes.

No item disponibilidade de frio, verificou-se que apenas a cidade de Campina Grande apresentou melhores condições, com 35,4\% de conformidade. Os municípios de Esperança, Areia e Bananeiras apresentaram conformidade para estocagem de alimentos em $22,4 \%, 16,5 \%$ e $0,9 \%$, respectivamente. É importante ressaltar que a ausência de energia elétrica nos boxes das feiras livres, embora seja preocupante do ponto de vista de saúde pública, parece uma constante em todo Brasil. A falta de energia elétrica impede que estruturas geradoras de frio para conservação de alimentos, como balcões frigorigênicos, não possam ser instalados. Dessa forma, alimentos perecíveis como carnes, aves e pescados ficam expostos e apresentam temperaturas inadequadas de comercialização, não se mostrando seguros para o consumidor final. Na avaliação da ventilação e exaustão do local, os quatro municípios apresentaram conformidade em mais de $75 \%$ dos boxes avaliados, sendo basicamente o único item em conformidade na análise dos aspectos físicos (Figura 1).

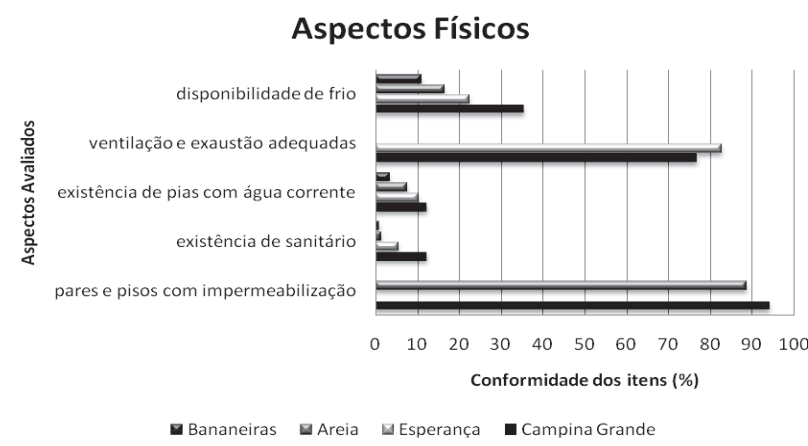

Figura 1: Aspectos físicos observados nas feiras livres de Campina Grande, Esperança, Areia e Bananeiras, localizados no Estado da Paraíba, 2012.

A segunda avaliação do estudo foi em relação aos aspectos higiênicos. Os itens avaliados foram: condições das instalações, responsabilidade pela higiene do local, higienização das estruturas utilizadas na feira, treinamento dos feirantes e uso de avental e touca pelo feirante.

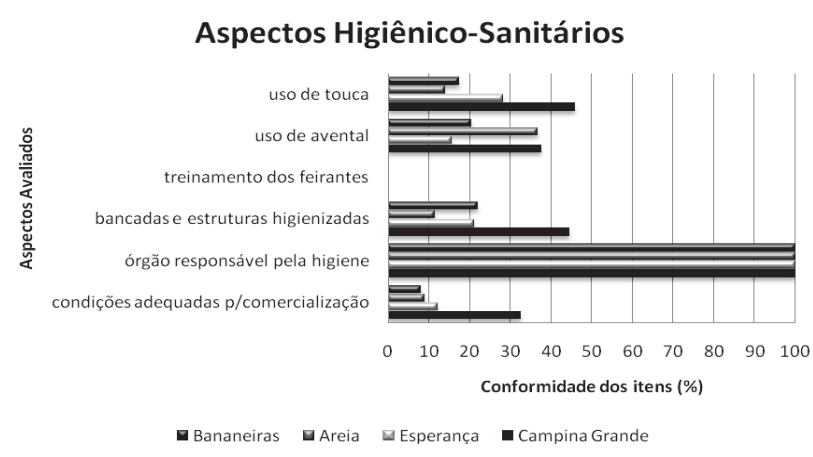

Figura 2: Aspectos higiênico-sanitários observados nas feiras livres de Campina Grande, Esperança, Areia e Bananeiras, localizados no Estado da Paraíba, 2012. 
Na Figura 2 observa-se que em relação às condições adequadas para comercialização os municípios de Campina Grande, Esperança, Areia e Bananeiras apresentaram taxa de conformidade de $32,5 \%, 12,1 \%, 8,9 \%$ e $8,0 \%$, respectivamente. Essa condição é bastante insatisfatória, tendo em vista que o principal tipo de alimento comercializado é perecível. Um item que se mostrou satisfatório nos quatro municípios foi a responsabilidade pela higiene do local. Em todos eles, havia um órgão vinculado ao município para realização da limpeza após os trabalhos de feira. No entanto, não foi verificado em nenhum município realização de serviços de limpeza durante a comercialização dos alimentos; este se fazia apenas após o término da feira livre. Para o item bancadas e estruturas higienizadas os resultados foram insatisfatórios, tendo em vista que em nenhum dos municípios apresentou conformidade de pelo menos $50 \%$ dos itens avaliados. A falta de treinamento dos feirantes em relação às boas práticas de manipulação e conservação de alimentos também não foram observadas em nenhum dos quatro municípios estudados.

Estudo realizado por Silva, Matté e Matté (2008) avaliando a qualidade sanitária de pescados em feiras livres de São Paulo verificaram que os feirantes não acatavam integralmente a padronização de vestimentas e mostravam falhas em relação ao asseio e higiene pessoais, bem como no cuidado com a manipulação do pescado. Esses dados foram bastante semelhantes a este estudo, uma vez que o cuidado com o uso de avental e touca foi ligeiramente satisfatório. $\mathrm{O}$ município que apresentou melhores resultados foi Campina Grande, com taxa de 37,7\% de uso de avental e 45,8\% de uso de touca. O município que apresentou os resultados mais insatisfatórios no quesito uso de avental foi Esperança, onde apenas $15,7 \%$ dos comerciantes utilizavam esta vestimenta. O município de Areia apresentou o resultado menos satisfatório em relação ao uso de touca: apenas 13,9\% dos feirantes a utilizavam durante a comercialização de alimentos.

Em estudo semelhante de Beir e Silva (2009), a utilização de adornos durante a produção era uma prática constante na feira livre de Brasília, uma vez que em 69,6\% dos locais os trabalhadores usam algum tipo de adereço, como avental. Em trabalho desenvolvido por Souza (2006), o autor afirma que o maior problema na contaminação de alimentos são os manipuladores, em que $68 \%$ dos resultados se mostraram regulares e ruins. De fato, o ambiente inadequado para comercialização de alimentos associado à práticas inadequadas de manipulação de alimentos é uma situação rotineira encontrada na maioria das feiras livres do país, o que compromete a qualidade e segurança dos alimentos fornecidos ao consumidor final.

Em estudo realizado na Bahia, os autores relataram que existe uma dificuldade dos feirantes em explanar sobre o tema da contaminação microbiológica (ALMEIDA; PENA, 2011). Segundo eles, para os feirantes os contaminantes físicos visíveis e os odores desagradáveis são os possíveis transmissores de doenças e impurezas. Essa realidade parece uma constante nas feiras livres, uma vez que não existe preocupação em treinar e capacitar os manipuladores de alimentos sobre higiene e manipulação adequada dos alimentos.

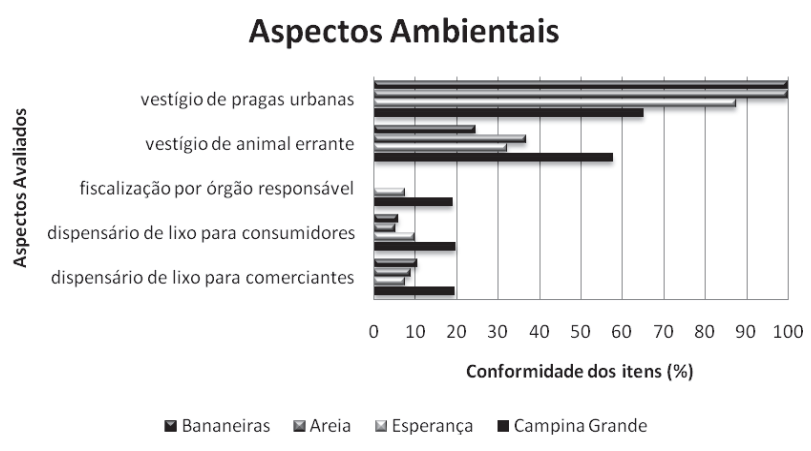

Figura 3: Aspectos ambientais observados nas feiras livres de Campina Grande, Esperança, Areia e Bananeiras, localizados no Estado da Paraíba, 2012.

Nos aspectos ambientais, observados na Figura 3, percebe-se que o dispensário de lixo para comerciantes e consumidores é bastante deficiente. Neste quesito os municípios avaliados atingiram conformidade em menos de $20 \%$ em cada um dos itens. Durante as feiras livres observou-se em sua quase totalidade a ausência de fiscalização por órgãos responsáveis durante o momento de feira livre. Observou-se ainda a presença de animais errantes numa taxa de 57,7\% em Campina Grande e 100\% de vestígios de pragas urbanas nos municípios de Areia e Bananeiras.

Xavier et al.(2009) estudaram as condições higiênicas de uma feira livre no município de Governador Valadares, em Minas Gerais. Os autores sugerem que deve haver uma ação mais intensificada da Vigilância Sanitária. Os autores também sugerem maior conscientização dos feirantes, utilizando ferramentas como palestras, cursos e panfletos. Esses dados são parecidos aos encontrados neste estudo, uma vez que este tipo de ação também deveria ser implantada nas feiras do Agreste Paraibano.

O estudo de Vaz et al.(2003) também confirmou que os aspectos ambientais nas feiras livres na Bahia não são satisfatórios. Os autores relatam que a presença de resíduos sólidos dispostos nas vias de acesso às barracas gera desconforto, expõe os alimentos à vetores de doenças como mosquitos e cães, além de gerar forte mau cheiro, o que desestimula o consumo. Esses dados são bastante semelhantes aos encontrados nas feiras livres da Paraíba, uma vez que as mesmas condições foram observadas, principalmente em relação à presença de insetos e circulação de animais errantes.

\section{Aspectos Organizacionais}

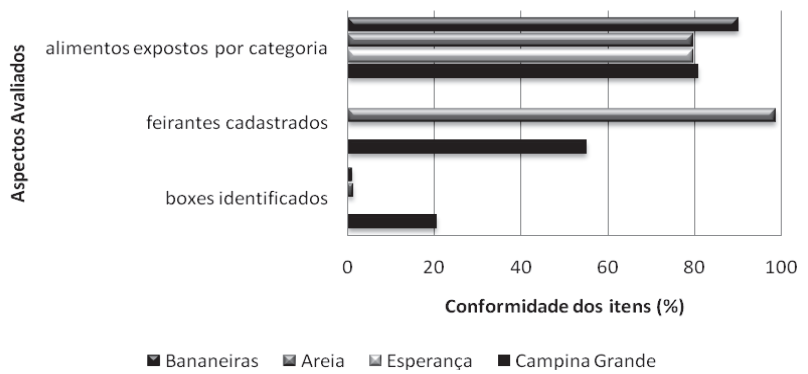

Figura 4: Aspectos organizacionais observados nas feiras livres de CampinaGrande, Esperança, Areia e Bananeiras, localizados no Estado da Paraíba, 2012. 
A Figura 4 mostra que em relação à organização do espaço físico o município de Campina Grande obteve a melhor regularidade. Este município foi o que apresentou maior taxa de feirantes cadastrados junto aos órgãos municipais $(55,1 \%)$, além de apresentar $80,9 \%$ dos boxes comercializando alimentos por categoria. Este fato é interessante por permitir o agrupamento dos alimentos em determinadas categorias, minimizando as eventuais contaminações cruzadas. Na avaliação da identificação dos boxes, os quatro municípios foram insatisfatórios, pois em nenhum dos quatro municípios a identificação foi maior que $20 \%$. Percebeu-se ainda que nos municípios de Esperança e Bananeiras 100\% dos feirantes não possuíam nenhum tipo de cadastro junto aos órgãos competentes e que em Bananeiras nenhum boxe possuía identificação.

Em trabalho realizado por Ferreira et al. (2010), os autores verificaram que a forma de apresentação das carnes à venda estava muito aquém das condições ideais. Segundo eles, as carnes ficavam expostas sobre estruturas de madeira, sem proteção contra insetos, dentro de sacos plásticos sobre superfícies improvisadas próximas ao chão ou ainda em bacias. Este tipo de situação também foi encontrada em três cidades desta pesquisa: Esperança, Areia e Bananeiras. Nestes locais a exposição da carne à temperatura ambiente, sem qualquer proteção, foi atrativo para diversas pragas urbanas e animais errantes, dentre eles insetos, roedores, pombos e cães.

Minnaert e Feritas (2010) afirmaram que em feiras livres de Salvador, a limpeza do lugar é utilizada como estratégia de marketing e não como um aspecto da saúde. Segundo os autores, os feirantes acreditam que a manutenção da limpeza deve ocorrer de acordo com a demanda dos fiscais e para atrair mais fregueses e não porque a falta de higiene contamina o alimento e provoca doenças. Esse tipo de pensamento é preocupante e mostra despreparo dos feirantes frente à atividade de comercialização de alimentos seguros.

\section{Conclusão}

As quatro feiras livres visitadas neste trabalho mostraram-se inadequadas como fonte de comércio para alimentos perecíveis. Investimentos são necessários não apenas para melhorar a condição estrutural das feiras, mas principalmente para garantir condições seguras de comercialização de alimentos.O treinamento e conscientização dos feirantes sobre adoção de práticas para garantir a comercialização de alimentos seguros se faz necessário nos quatro municípios.

Por ser importante fonte de renda, apresentar grande circulação de pessoas e expor alimentos perecíveis, maior cuidado deve ser dado a este tipo de comércio. A adoção de práticas sócio-político-organizacionais poderiam contribuir para melhoria da qualidade do serviço, além de fortalecer a geração de renda na região e garantir alimento com qualidade e segurança para o consumidor final.

\section{Referências}

ALMEIDA, M. D.; PENA, P. G. L. Feira livre e risco de contaminação alimentar: estudo de abordagem etnográfica em Santo Amaro, Bahia. Revista Baiana de Saúde

Pública, v. 35, n. 1, p. 110-127,2011.
BEIRÓ, C.F.F.; SILVA, M.C. Análise das condições de higiene na comercialização de alimentos em uma feira livre do Distrito Federal. Universitas:Ciências da Saúde, v. 7, n. 1, p. 13-28, 2009.

BRASIL. Ministério da Saúde. Agência Nacional de Vigilância Sanitária. Resolução n ${ }^{\circ} 216$, de 15 de setembro de 2004. Dispõe sobre Regulamento Técnico de Boas Práticas para Serviços de Alimentação. Diário Oficial da União. Brasília, DF, 2004.

CAPISTRANO, D.L.; GERMANO, P.M.L.; GERMANO, M.I.S.Feiras livres do município de São Paulo sob o ponto de vista legislativo e sanitário. Revista Higiene Alimentar, v. 18, p.37-42, 2004.

CORREIA, M.; RONCADA, M.J. Características microscópicas de queijos prato, mussarela e mineiro comercializados em feiras livres da cidade de São Paulo. Revista de Saúde Pública, v. 31, n. 3, p. 296-601, 1997.

DIB, J.A.Efficientconsumer response (ECR): uma estratégia para o varejo de bens de consumo de massa. Revista Administração, v. 32, n.2 p. 14-22, 1997.

ENCICLOPÉDIA LUSO-BRASILEIRA, volume 8, p.552. 1995.

FERREIRA, F.R.B.et al. Condições higiênico-sanitárias das carnes comercializadas em feiras livres de municípios da zona da mata norte-PE. 2010. In: X Jornada de Ensino, Pesquisa e Extensão da UFRPE, 10. Anais...2010.

\section{GERMANO, P.M.L.; GERMANO, M.I.S. Higiene e vigilância sanitária de alimentos: qualidade das matérias-primas, doenças transmitidas por alimentos, treinamento de recursos humanos. $2^{\circ}$ ed. São Paulo: Livraria Varela, 2000, 655p.}

HANASHIRO, A.et al. Qualidade higiênico-sanitária de alimentos de rua populares versus orientais comercializados em São Paulo. Revista NETDTA, v. 2, n. 6, p. 93-97, 2002.

MALLON, C.; BORTOLOZO, E.A.F.Q. Alimentos comercializados por ambulantes: uma questão de segurança alimentar. Publicatio UEPG, v. 10, n. 3-4, p. 65-76, 2004.

MASCARENHAS, G.; DOLZANI, M.C.S. Feira livre: territorialidade popular e cultura na metrópole contemporânea. Ateliê Geográfico, v. 2, n. 4, p. 72-87, 2008.

MINNAERT, A.C.S.T.; FREITAS, M.C.S. Práticas de higiene em uma feira livre da cidade de Salvador (BA). Ciência \& Saúde Coletiva, v.15, supl. 1, p. 1607-1614, 2010.

RIBEIRO, E.M.et al. Programa de apoio às feiras e à agricultura familiar no Jequitinhonha mineiro. Agriculturas, v. 2, n. 2, p. 5-9, 2005. 
SILVA, E.M.et al. O desenvolvimento econômico e social da feira livre de Umbaúba, 1989 a 2009. Trabalho de Conclusão de Curso da Universidade Tiradentes para obtenção do grau de bacharel em Serviço Social, apresentada à Universidade Tiradentes. 2009.

SILVA JÚNIOR, E.A.Manual de controle higiênicosanitário em alimentos.4a.ed. São Paulo: Livraria Varela, 2001, 475p.

SILVA, M.L.; MATTÉ, G.R.; MATTÉ, M.H. Aspectos sanitários da comercialização de pescado em feiras livres da cidade de São Paulo, SP/Brasil. Revista do Instituto Adolfo Lutz, v. 67, n. 3, p. 208-211, 2008.

SOUZA, L.H.L. A manipulação inadequada dos alimentos: Fator de contaminação. Revista Higiene Alimentar, v. 20, n. 14, p. 32-39, 2006.

VAZ, L.M.S. et al.Diagnóstico dos resíduos sólidos produzidos em uma feira livre: o caso da feira de Tomba. Sitientibus, v. 28, p. 145-159, 2003.

XAVIER, A.Z.P. et al.Condições higiênico-sanitárias das feiras-livres do município de Governador Valadares. Trabalho de Conclusão de Curso da Universidade Vale do Rio Doce para obtenção do Grau de Bacharel em Nutrição, apresentada à Faculdade de Ciência da Saúde da Universidade Vale do Rio Doce. 2009. 94p.

Recebido em 17/07/2014

Aceito em 17/12/2014 